\title{
Historical Perspectives on Medical Professionalism in the Caribbean
}

Dexnell Peters ${ }^{1} \&$ Farid F Youssef ${ }^{2}$

\author{
Affiliations:

\section{Correspondence:} \\ Faid F Youssef \\ Department of Preclinical Sciences \\ Faculty of Medical Sciences \\ The University of the West Indies \\ St. Augustine \\ Trinidad \& Tobago \\ Office Tel: (868) 645-3232 Ex 4618 \\ Office Fax: (868) 645-3615 \\ Emil: farid.youssef@sta.uwi.edu
}

${ }^{1}$ Department of History, John Hopkins University, Baltimore, MD, USA

${ }^{2}$ Department of Preclinical Sciences, Faculty of Medical Sciences, The University of the West Indies, St. Augustine, Trinidad \& Tobago

Short Title: History of Medical Professionalism in the Caribbean

Synopsis: This article explores the historical development of medical professionalism within the Caribbean region providing insight into the factors that have shaped our community of physicians and directions for future development in this increasingly important aspect of medical training. 


\section{$\underline{\text { Abstract }}$}

This paper provides an historical overview of the development of perspectives on medical professionalism and the medical profession in the Caribbean. Two historical periods, colonial and postcolonial, will be explored for continuities and changes in perspectives. Recently, concern over the dilution of medicine's humanistic qualities has caused increased interest in medical professionalism and ignited a wider movement to reform the profession. Medical education curricula are under renovation as issues of professionalism are now being openly raised among medical practitioners and students to ensure that the medical profession's service to society is uncompromised. In this context, some scholars have felt that awareness of the history of the medical profession could play a significant role in humanizing medicine and fostering greater professionalism. Much of the emerging discussion on medical professionalism has occurred mainly in developed countries, namely Britain and the United States. The wider developing world, including the Caribbean, has fallen behind in this process. There is a lack of historical or contemporary works addressing the medical profession issues of medical professionalism in the Caribbean. This paper will begin to fill this gap. 


\section{Introduction}

Medical professionalism is a new but flourishing subject of study. Concern over the dilution of medicine's humanistic qualities has caused increased interest in the subject and ignited a wider movement to reform the profession (1). Medical education curricula are under renovation as issues of professionalism are now being openly raised among medical practitioners and students to ensure that the medical profession's service to society is uncompromised. In this context, some scholars have felt that awareness of the history of the medical profession could play a significant role in humanizing medicine and fostering greater professionalism (2-3). Medical students need to be reminded of the early foundations of the profession, the Hippocratic tradition and the long journey towards its present state, specific to local contexts. Many historical works have been written, some of which focus on the historical evolution of medical professionalism and these give an overview of the earliest principles and values of the profession that have become its core tenets (4-5).

The wider developing world, including the Caribbean, has fallen behind in this process. Much of the emerging discussion on medical professionalism has occurred mainly in developed countries, namely Britain and the United States. In the Caribbean there are no existing historical or contemporary works addressing specific issues of medical professionalism. Putting medical professionalism aside, works on the medical profession in the Caribbean are also lacking. To date, for example, there is no comprehensive work on the history of the medical profession, much less medicine, in the Caribbean, especially in the modern era and only few works exploring the history of the profession in individual Caribbean countries. This paper will attempt to give a brief 
historical overview of the development of perspectives on medical professionalism and the medical profession specific to the Caribbean. Two periods of history, colonial and postcolonial, will be explored for continuities and changes in perspectives.

Medical professionalism of course, has proved difficult to define, resulting in numerous attempts of definition by scholars (6). Nevertheless, there remains a lack of consensus on what is professionalism and therefore no universal definition exists. Dennis McDonagh provides one of the many attempts at a definition:

Medical professionalism is our behavior as (practitioners). It is how we conduct ourselves as (practitioners) in our interactions with our patients and society. Medical professionalism is a behavior that is predicated on our personal beliefs and our ideas ... Medical professionalism is greatly influenced by our contemporaneous social values and norms. Therefore, it remains a flexible concept from age to age, despite maintaining a core set of values (7).

McDonagh's definition is useful for this paper in its acknowledgement of the dynamism of professionalism, that it is drawn from different sources whether cultural, technical or ethical to name a few, but also how it changes over time. Certain expectations, however, were always held of medical practitioners. Here Cruess and Cruess' definition of medical professionalism as a contract held between medical practitioners and society also proves useful (8). Medical practitioners have always been subjected to expectations from society. They were expected to be altruistic, to have the best interests of the individual and society at large, to do good and to never do harm. As far back as the fourth century B.C.E., such expectations about medical practitioners were conveyed in what is now 
popularly known as the Hippocratic oath. This paper will use the term 'medical professionalism' loosely to mean contemporary perceptions of how the service of medical practitioners met the expectations of Caribbean society.

\section{The Colonial Caribbean}

\section{I) The Pre-Emancipation Era}

Colonialism has been instrumental in shaping the present day medical profession. Not discrediting the significant history of the pre-Colonial Caribbean, the arrival of Europeans by the end of the fifteenth century led to widespread transformation of Caribbean society. In most territories the indigenous population rapidly dwindled, thereby decreasing their influence on colonial society. Colonization brought a large number of people together and created a number of new health concerns. The disease environment and overall conditions increased the demand for medical practitioners from Europe. Despite a high demand, in the early days, few practitioners migrated to the Caribbean and the few that did catered mostly to the needs of the white elite. By the late eighteenth century, however, there were concerted efforts to improve the health of the enslaved population influenced by an increase in slave prices and agitation for the abolition of the slave trade (9). The remedy to the situation was to improve the health of existing enslaved persons and, consequently, there was an influx of medical practitioners.

The enslaved community understandably distrusted many of these incoming practitioners. While this period also saw improvements in their treatment, there was still a fair amount of disingenuous practitioners. There was a general impression that doctors were using the enslaved as guinea pigs to test out their various theories or that they were 
ignorant to the medical issues in the Caribbean. Fortunately, there were alternatives. Enslaved or 'negro doctors' provided medical care. Barry Higman notes that there was a belief that some 'negro doctors' had comparable medical knowledge to white doctors and also were more successful in gaining cures (10). For example, many Afro-Caribbean healers treated enslaved persons with the highly contagious 'yaws' with much success and European doctors often borrowed the remedies of these practitioners (11).

The Caribbean medical world was, however, not simply a black or white, European or African one. Many white doctors collaborated with Africans in providing services. In slave hospitals, for example, the advice and orders of white doctors were implemented by various African or colored practitioners. Some white doctors also sought to incorporate aspects of African medicine into their professional practice. Both European and African medicine were therefore sought after. Jerome Handler notes that enslaved persons made use of services from European practitioners but they often relied on support from traditional healers due to a lack of trust (12). The issue of trust becomes more significant given the unrestrained, though sometimes criticized, practice of doctors in the Caribbean.

Until the nineteenth century medical practitioners in the Caribbean were largely unregulated. There was no practice requirement and anyone could and did practice if they wished. A wide range of persons therefore served the public. Some came with medical degrees or certification. Others underwent various kinds of apprenticeships. Some had little to no knowledge or experience of medicine. The result of this mixed pot was the development of very negative views towards medical practitioners. Some settlers simply refused to be treated believing that these medical practitioners were the reason for much 
death in the Caribbean. In many cases the presence of diseases like Yellow Fever - which medical practitioners struggled to effectively treat, mostly due to their ignorance of it made death inevitable at times. Therefore, it could be said that the limitations of the medical sciences rather than misconduct from medical practitioners may have helped to perpetuate negative perceptions. Nevertheless, some practitioners were blatantly irresponsible, dishonest. J. R. McNeil notes that people "had every reason to keep their distance from doctors. (13)” Many of those arriving to practice medicine in the Caribbean were in pursuit of wealth. Some regularly treated illnesses which they knew nothing about (14). The scarcity of medical practitioners in addition to the unregulated Caribbean space ensured that despite shortcomings great profit could be gained.

In the Caribbean many medical practitioners, like others who travelled to the region in the early modern period, were seeking wealth. Opportunities for the wonton pursuit of wealth was greater in the region, given the lack of regulatory bodies prior to the nineteenth century. One physician in Jamaica, William Boseley noted in 1789 that while many of the physicians in Jamaica might be men of science and good education he felt that what plagued the medical profession was that the acquisition of wealth seemed to be the principal goal (9).

By the early nineteenth century colonial officials took greater note of the ills of the medical community and sought to improve it. In 1814 Trinidad Governor Ralph Woodford issued a proclamation noting that

"it has become necessary to prevent the indiscriminate introduction and admission of persons to practice Medicine and Surgery in the said Island, 
without due proof of their having acquired or being possessed of a competent knowledge in such their profession and practice ... (15)"

He established a medical board to evaluate medical professionals, grant licenses and prosecute unlicensed practitioners. Jamaica followed later in 1832 when a college of physicians and surgeons was established to improve the respectability of the profession. These efforts proved largely ineffective in regulating the wide range of persons who practiced. Most importantly, the efforts of colonial authorities focused solely on competence. Issues of character, morality and ethics, even among those with medical degrees, were therefore left unaddressed. As far as the law was concerned, a good practitioner was a medically competent one.

\section{II) Post-Emancipation}

In the post emancipation period, there was a greater need for healthcare in the Caribbean, especially among the newly freed population. Rita Pemberton argues that emancipation resulted in a diminishing community of European-trained doctors and therefore a more expensive and scarce supply of medical services which planters manipulated to secure control over the newly freed labor supply (16). The establishment of the Barbados General Hospital in 1844 provides a good example of the postemancipation demand for medical services. Within the first few years the hospital admitted an average of nearly 300 patients, 72 percent black. By the end of the nineteenth century this number increased to an average of over 3, 000 patients. Overcrowding became an acute problem and some began to be turned away for want of vacant beds 
(17). All the doctors in the Barbados General Hospital were white and mostly recruited from England up to the early twentieth century. White, European trained doctors were a premium in the post-Emancipation period. For non-elite or less wealthy persons, encounters with these medical doctors were almost exclusively conducted in conditions of dependence. Either they were objects of charity with little autonomy or perhaps they were seen by a doctor paid for by their employers on the plantation.

European-trained doctors, therefore, came into increasing demand but their services were still scrutinized. Bridget Brereton notes that grievances related to medical care were important causes in post-emancipation riots of the 1870s in the Windward Islands (18). Deductions were made from the salaries of laborers in Tobago for care from a private physician who practiced in the Windward district. The laborers did not object to medical care but rather the large deductions. They may still have put up with the expense if the doctor had not been so unpopular, mainly due to a growing reputation for negligence.

In the midst of major concerns about the medical community, colonial states continued to make efforts to improve the medical profession in the post-emancipation era. By the late nineteenth century Trinidad had produced four ordinances aimed at regulating the medical profession. The final ordinance in 1898 was described as the most "stringent medical ordinance or Act enforced in the empire" by a member of the United Kingdom General Medical Council. It went to greater lengths to protect the public from the dangers of persons who were unqualified or unfit to practice. Most interestingly, the ordinance added a criterion for admission based on a person being of good character. Dr. Richard Thorne, member of the council, noted that this added criterion for licensing 
persons along with an examination was a "precedent of very great importance.(19)" Colonial officials were no longer simply concerned about competence but also with conduct. It is particularly indicative of what they felt was negatively impacting the medical community.

Not surprisingly, the post-emancipation period saw a slow but steady growth of Caribbean born but also non-white medical practitioners. The majority Caribbean population preferred to be treated by their own. These new practitioners, though local, were trained abroad mainly in Europe but also in the United States (20). They returned with elevated privilege in society and, for some, it was why they choose to pursue medicine. The ills of colonial society made such motivations rampant, mainly due to massive inequalities between the elite and working classes. Among the working class in particular there was poverty and social limitations. The desire to rise above these conditions was, therefore, present among most. For many, this dream could be achieved through education and entrance into a profession. Eric Williams, former Prime Minister of Trinidad and Tobago, describes this colonial society well in his autobiography, Inward Hunger. The point is perhaps most evidently made as he describes his showdown with his father over his decision to study history at Oxford University. Williams writes that his father's "wish was that (he) should study medicine or law, preferably the former." He continues "He wanted me to have 'independence', as he put it. (21)" There was no altruistic consideration in Williams' father's argument; he merely wanted him to better himself. Motivations of social mobility therefore only exacerbated existing problems within the medical community. 
Samuel Selvon in his historical novel, A Brighter Sun, based in the 1930s, gives us a glimpse of these new practitioners. He writes of some interactions with white and non-white doctors in Trinidad in the early twentieth century. The protagonist's (Tiger) wife is gravely sick due to complications with a pregnancy. He ventures out in the middle of the night to seek medical treatment for her. Tiger, of East Indian descent, first seeks out an Indian doctor. His first impulse after telling the doctor his wife is very sick is to assure the doctor that he will pay him well. Despite Tiger's call for urgent attention, the doctor brushes him off and says he will come in the morning. Disappointed, Tiger returns to the taxi that brought him. He is confused at the Indian doctor's lack of concern and asks the taxi whether he was sure it was an Indian doctor. The driver confirms and further notes "Is so wen yuh poor and not in society, papa ... boy, if I tell yuh about some of de doctors in dis place, yuh dead.(22)” He next goes to a 'creole' doctor but receives a similar response. Tiger eventually receives a positive response from a white doctor who recognizes the situation as severe and agrees to come see his wife immediately. Selvon's historical novel highlights the degree to which there was an expectation that more creole practitioners would lead to better care for the masses. But these new practitioners did not always satisfy this expectation. Ultimately, more systematic change proved necessary. A 1938 West Indian Commission established to investigate the Caribbean riots of the 1930s deemed health as one of the most severe concerns. It highlighted the need for more locals to join the health force and to rise to leadership positions. It also recommended the creation of a local medical school(23).

The establishment of a medical school in the Caribbean was crucial for the medical profession. It was formulated in the age of decolonization along with a high 
spirit of Caribbean regionalism that filled the air and ultimately culminated in the establishment of the West Indian Federation. The process towards the new medical school began in 1943 and led to the erection of the medical department of the University College of the West Indies (UCWI) in Jamaica which opened its doors in October 1948. Its students, drawn from various parts of the region, were symbolic of the emerging Caribbean nation.

The new school was confronted by negative attitudes among Caribbean people. Colonial subjects had become accustomed to being serviced by foreign educated practitioners and as a result some questioned the school's quality in comparison to those overseas. Special emphasis was therefore placed on knowledge and competence in the new school. The results of the first examinations were exceptional, a trend that continued in later years. What followed was a shift in attitudes of 'doubt and criticism' to 'pride and confidence'(24). It is not surprising that the early medical students of the UCWI did well. Decolonization in the Caribbean inspired a desire and confidence in governing one's own affairs and influenced a positive work ethic and competitive drive among Caribbean people.

The mid-twentieth century was also a watershed time for the global medical profession. It was around this time that the World Medical Association (WMA) was established (1947). One of its first major concerns centered on the general state of medical ethics across the globe. Evidence of medical atrocities by the Nazis, revealed after the Second World War, indicated the clear need for reform. The WMA then set about working on a charter of medicine, essentially a modern version of the Hippocratic Oath, that doctors around the world would adopt upon earning their medical degree. The 
result of these efforts was the 'Declaration of Geneva' in 1948, which later gave way to an international code of ethics the following year.

This new global context did not have an immediate formal impact on the UCWI. While issues of medical ethics and professionalism were not directly discussed in any formal capacity, they would however form part of informal consideration. Walsh and Abelson note that in the 1950s "the concept of professionalism suffused the work of doctors but was rarely discussed or addressed.(25)” As a result, an emphasis on medical professionalism, though not explicitly addressed, was evident at the university. One of the committee members of the Irvine Committee noted that the UCWI was established with the intent of encouraging "the development of a West Indian outlook and ... the attainment of the highest ethical and academic standards(26).” There was, however, no formal effort to foster these ideals nor did the curriculum ever concern itself with such content. It was rather an unspoken understanding. Dr. Al Cotterel, a UCWI alumni from the third batch of medical students to graduate, confirms this point of view. Commenting on issues of medical professionalism during his time at UCWI he noted:

"You know that (issues of medical ethics and professionalism) did not come up in the curriculum at all. I think it should be in the curriculum but it did not arise in our time. I think most of us had this sort of grounding at home and the schools with which we went. There was a sort of background awareness to our sort of responsibility to the greater society. It was never taught to us.(27)” 
The spirit of decolonization in the Caribbean and the significance of the new medical school ensured that issues of medical professionalism featured as part of a hidden curriculum. William Pinar describes the hidden curriculum as the "ideological and subliminal message(s) presented within the overt curriculum, as well as a by-product of what is not offered - the null curriculum (28).” Dr. Cotterel noted for example one professor whom he, and he believed many others, felt was a good teacher and was well respected. Dr. Cotterel was particularly intrigued by his approach to medicine. He constantly reminded students of their responsibilities to patients, often encouraging them to put themselves in the shoes of their patients. This approach invoked vigorous debate among his peers, and that while some agreed others did not. Dr. Cotterel also shed insight on another faculty member who was not considered a good doctor and whose approach was considered quite the opposite to being patient-centred. He noted an instance when the doctor boldly ventured into medical care that was known to be well outside of his competence with negative results. For Dr. Cotterel this experience helped him to see an example of the kind of doctor not to become. Essentially, his comments shed some insight into the hidden curriculum at the UCWI and help us to look at how attitudes to medical professionalism developed in the early formation of the Caribbean medical profession.

The establishment of the UCWI saw a concerted effort towards systematic change in the medical community. New medical professionals were now trained in a local environment as part of a new regional nation building process. There was no distance from the people these new practitioners would actually serve, unlike the earlier days of colonialism. This was an era where more opportunities were opening up and people were 
increasingly responsible for making and managing society. The accomplishment of the UCWI also challenged some of the medical profession's old concerns. The output of more doctors into society helped to challenge the power and status of the few practitioners in the Caribbean at the time. Many of the early graduates of the UCWI went on serve at various levels in the medical profession and in the society. The fact also that no need was felt for explicit attention to issues of medical professionalism meant this was not a large concern among students or faculty. Looking ahead, however, it is clear that old concerns for medical professionalism persisted. It may be safe to say then that the UCWI and decolonization may have helped to mask or mitigate some of these concerns.

\section{The Post-Colonial Era}

Increasing concerns about medical professionalism and a prevailing negative view of the medical profession continued to mark the post-colonial era. Cruess and Cruess note that in the 1960s and 70s medical authority and assumptions of altruism were challenged. They write that "(some) argued that medicine had abused its monopoly to further its own interests, had self-regulated poorly, and that its organizations were more interested in serving their members than society(8).”

These concerns were increasingly present in the Caribbean. Gordon Lewis points out that reports on medical services painted a negative picture. In the Bahamas, for example, a 1960 report noted that "the temptation of the medical profession to deal more with the wealthy patient had produced a general situation in which some twenty-one inhabited islands had to do with the services of only seven qualified practitioners. (29)" A 1977 study in Trinidad and Tobago revealed that rural areas still used or preferred creole 
as opposed to doctor medicine. Those interviewed noted a general distrust of doctors as one of the reasons for this preference (30).

A shortage of medical practitioners has also remained a persistent problem in the post-independence era of the Caribbean. The emergence of the brain drain from so-called developing to developed countries has only exacerbated this perennial shortage. The Caribbean remains one of the most affected regions in the world (31). The problem has been most acute in Jamaica. A 2005 study revealed that 41.4 percent of Jamaica's medical school graduates migrated to other developed countries, the largest percentage of all countries in the study (32). Many of those migrating do so in pursuit of better opportunities and conditions or because of disenchantment with the local healthcare system. Such reasons are indication of the persistence of old colonial motivations of upward social mobility and self-improvement. These motivations superseded the commitment to serving the nation and region that first inspired medical students of the UCWI, an issue of medical professionalism in itself.

As a result of these ongoing concerns, Caribbean nations continued to make efforts to improve the medical profession. The post-colonial era brought a new period of transformation. Governments sought to re-shape institutions to acquire national rather than colonial relevance. Independence influenced many attitudes and developments in the Caribbean and in particular the management and improvement of the medical profession. Now independent parliaments created new medical legislation establishing (or reestablishing) medical boards, regulations and institutions. A new Medical Board Act, for example, was passed in Trinidad in 1960 and Jamaica and Barbados followed in 1972. These acts outlined specific activities that amounted to professional misconduct and 
displayed the increased effort to regulate and improve the image of the medical profession. Caribbean governments and medical boards have continued to make interventions in recent times. Legislation and codes of conduct or ethics for the medical profession have been produced and renovated. Most recently, for example, Trinidad reissued its code of ethics in 1990 and Jamaica and Guyana produced a code of conduct in 2008.

In recent times, the global trend has been towards more deliberately raising issues of professionalism among current and upcoming medical professionals. As a result courses in medical professionalism have been embedded into medical curricula. Since the creation of the UWI medical school, its medical curriculum has undergone little formal change in updating the curriculum to focus on issues of medical professionalism. Only very recently the Caribbean Accreditation Authority for Education in Medicine and other Health Professions (CAAM-HP) made a specific request for focused instruction and exposure to issues in professionalism and ethics. In 2013, the UWI St. Augustine medical school began a compulsory series of undergraduate courses in professionalism, ethics and communication.

\section{Conclusion}

Ultimately, this historical overview has revealed the persistence of ethical and moral concerns about medical practitioners in the Caribbean from the colonial era to the present day. Recent efforts to give explicit attention to medical professionalism for medical students and professionals is a progressive step in a long tradition of efforts to curb concerns. Efforts first focused on weeding out incompetent or unqualified practitioners and then shifted to describing values medical professionals should adopt. 
Most recent efforts seek to raise awareness of and, more importantly, teach these values to the medical profession. This more deliberate intervention goes in tandem with the current perception of an increasing crisis of medical professionalism in the Caribbean and across the globe. Medical practitioners in the Caribbean need to be aware of the evolving state of the profession and how their actions impact the fulfillment of medicine's contract with society and ultimately regional development. This historical overview provides a brief glimpse at the medical profession's progression thus far and leaves the onus upon present and upcoming medical practitioners to write the next step. 


\section{References}

1. Martin C. Okay, Well How about Applied Liberal Education? Making a Case for Humanities through Medical Education. Phil Educ. 2011; 295-304.

2. Warner JH. The humanising power of medical history: responses to biomedicine in the 20th century United States. Med Humanit. 2011; 37: 91-6.

3. McCullough LB. Taking the History of Medical Ethics Seriously in Teaching Medical Professionalism. Am J Bioethics. 2004; 4: 13-4.

4. Applebee G. A Brief History of Medical Professionalism - and Why Professionalism Matters. Cont Pediat. 2006; 53-64.

5. van Mook WNKA, de Grave WS, Wass V, O’Sullivan H, Zwaveling JH, Schuwirth LW, et al. Professionalism: Evolution of the concept. Eur J Intern Med. 2009; 20: e81-4.

6. Birden H, Glass N, Wilson I, Harrison M, Usherwood T, Nass D. Defining professionalism in medical education: A systematic review. Med Teach. 2014; 36 :47-61.

7. Mcdonaugh D. Medical Professionalism. NE Flo Med Suppl.. 2008; 6-7.

8. Cruess RL, Cruess SR. Professionalism and Medicine’s Social Contract with Society. VM. 2004; 6 (4).

9. Sheridan RB. Doctors and slaves: a medical and demographic history of slavery in the British West Indies, 1680-1834. Cambridge (Cambridgeshire); New York: Cambridge University Press; 1985.

10. Higman BW. Slave populations of the British Caribbean, 1807-1834. Kingston, Jamaica: The Press, University of the West Indies; 1995.

11. Paugh K. Yaws, Syphilis, Sexuality, and the Circulation of Medical Knowledge in the British Caribbean and the Atlantic World. Bull Hist Med. 2014; 88: 225-52.

12. Handler JS. Slave medicine and Obeah in Barbados, circa 1650 to 1834 . New West Indian Guide 2000; 74 :57-90.

13. McNeill JR. Mosquito empires: ecology and war in the Greater Caribbean, 1620 1914. New York: Cambridge University Press; 2010.

14. Weaver KK. Medical revolutionaries: the enslaved healers of eighteenth-century Saint Domingue. Urbana: University of Illinois Press; 2006. 
15. "Proclamation by Governor Ralph Woodford on the Medical Board of Trinidad, 20 $0^{\text {th }}$ December 1814,” Trinidad and Tobago Historical Society, Publication no. 554 (1941).

16. Pemberton R. Dirt, disease and death: control, resistance and change in the postemancipation Caribbean. História, Ciências, Saúde--Manguinhos. 2012; 47-58.

17. Cetinoglu O. A History of the Barbados General Hospital, 1844-1910. Carib Quart. 2014; 60 (1).

18. Brereton B. Post-emancipation protest in the Caribbean: the "Belmanna riots" in Tobago, 1876. Carib Quart. 54: 111-28.

19. The General Council of Medical Education and Registration. Lancet. 1898; 1594.

20. Sinnette C. Howard University College of Medicine and the Education of CaribbeanBorn Medical Doctors. J Natl Med Assoc. 1994; 86: 389-92.

21. Williams EE. Inward Hunger: The Education of a Prime Minister. London: Deutsch; 1969.

22. Selvon S. A Brighter Sun. Essex: Longman; 1972.

23. West India Royal Commission. West India Royal Commission, 1938-39:

Recommendations. London: H.M. Stationery Office; 1945.

24. D’Aeth R. The Growth of the University College of the West Indies. Brit J Edu Stud. $1961 ; 9$ :99-116.

25. Colin Walsh, Herbert T. Abelson. Medical Professionalism: Crossing a Generational Divide. Perspect Biol Med. 2008; 51 :554-64.

26. Priestly R. Making of a University : A paper read to the Cambridge branch of the Royal Empire Society in May 1951 by the Vice-Chancellor of the University of Birmingham. 1951.

27. Cotterel A. Interview with Dr. Al Cotterel. 2013.

28. Woloschuk W, Harasym PH, Temple W. Attitude change during medical school: a cohort study. Med Educ. 2004; 38: 522-34.

29. Lewis GK. The growth of the modern West Indies. new ed. Kingston ;Miami: Randle; 2004. 554 p. 
30. Aho W. Creole and Doctor Medicine: Folk Beliefs, Practices, and Orientations to Modern Medicine in a Rural and an Industrial Suburban Setting in Trinidad and Tobago, the West Indies. Soc Sci Med. 1977; 349-55.

31. Lofters A. The "Brain Drain” of Health Care Workers: Causes, Solutions and the Example of Jamaica. Can J Public Health. 2012; 103 :e376-8.

32. Mullan F. The Metrics of the Physican Brain Drain. N Engl J Med. 2005; 353: 18108. 